\title{
Cytotoxic Effect of Two Novel Platinum (II) Complexes on Breast Cancer: An in Vitro Study
}

\author{
Samad Akbarzadeh ${ }^{1}$, Fatemeh Ebrahimi ${ }^{1}$, Zeinab Faghih ${ }^{2}$, Ali Movahed ${ }^{1}$, Zahra \\ Faghih $^{3}$
}

${ }^{1}$ Department of Biochemistry, School of Medicine, Bushehr University of Medical Sciences, Bushehr, Iran. ${ }^{2}$ Pharmaceutical Sciences Research Center, Shiraz University of Medical Sciences, Shiraz, Iran. ${ }^{3}$ Shiraz Institute for Cancer Research, School of Medicine, Shiraz University of Medical Sciences, Shiraz, Iran.

\begin{abstract}
Background: With 1.36 million new cases in worldwide each year, breast cancer (BC) is the most common malignancy in the female. Among numerous chemotherapy drugs which are widely used for cancer therapy, platinum compounds are the most persuasive ones although challenges remain with the clinical use of them due to their side effects as well as intrinsic and acquired resistance. In the attempt to combat drug resistance, reduce cytotoxic side effects or find the drug for particular forms of cancer, over the years, thousands of other platinum (Pt) compounds i.e. carboplatin and oxaliplatin have been developed. Material and Methods: In this regard, we previously described the synthesis of some new platinum (II) derivatives with potential anti-cancer activities against BC. Here, we chose two of the best platinum(II) compounds, $3 \mathrm{~b}$ and $2 \mathrm{a}$, to further evaluate their cytotoxic activities against human BC cell lines, SKBR3, MCF-7, MDA-MB-231, and MBA-MB-468, with different molecular subtypes using a colorimetric MTT cytotoxic assay. Their cytotoxic activities were compared to cis-platin as a positive control. Results: Our result showed that both compounds had better cytotoxic effect against BC cell lines than cis-platin in particular in the case of triple-negative subtype. Conclusion: These results suggest these compounds as potentially valuable agents for the treatment of breast cancer patients.
\end{abstract}

Keywords: Platinum (II)- Breast Cancer- cytotoxic effect

Asian Pac J Cancer Biol, 3 (2), 47-50

\section{Introduction}

With 1.36 million new cases in worldwide each year, breast cancer $(\mathrm{BC})$ is the most common malignancy in the female. Surgery, radiation, chemotherapy and hormonal therapy are currently used for $\mathrm{BC}$ clinical treatments [1-2]. Among numerous chemotherapy drugs which are widely used for cancer therapy, Cis-platin is one of the most persuasive ones. Cis-plaltin was firstly approved by the FDA in 1978 [3-4] and has been broadly applied in the treatment of various human malignancies including bladder, breast, ovarian, lung, cervix, head and neck carcinoma and is best known for curing testicular cancer [5-6].

In spite of the great success of treating various kinds of cancer and although many types of cancers have recently received better prognosis, significant challenges remain with the clinical use of cis-platin due to their side
Submission Date: 01/09/2018Ａcceptance Date: 04/11/2018

effects i.e. neurotoxicity and nephrotoxicity [6]. as well as intrinsic and acquired resistance [7]. However, these days its combination with other cancer drugs have been applied as novel therapeutic strategies, in attempt to combat drug resistance, reduce cytotoxic side effects and/or find the drug for particular forms of cancer, over the years, thousands of other platinum $(\mathrm{Pt})$ compounds i.e. carboplatin and oxaliplatin have been developed. In this regard, we previously described the synthesis of some new platinum (II) derivatives with potential anti-cancer activities against $\mathrm{BC}$ [8-9].

Treatment protocols for $\mathrm{BC}$ are currently determined by the status of hormone/growth factor receptors expression (predominantly estrogen, progesterone and human epidermal growth factor (HER2) receptors). Accordingly, at least four BC subtypes are introduced. While the basal-like and Her2 enriched subtypes are the benefits of hormone therapy, the lack and/or weak

Corresponding Author:

Dr. Zahra Faghih

Shiraz Institute for Cancer Research, School of Medicine, Shiraz University of Medical Sciences, Shiraz, Iran

Email: faghihz@sums.ac.ir 
expression of these receptors, in triple negative $\mathrm{BC}$ (TNBC), needs more toxic chemotherapy. Here, we chose two of the best platinum(II) compounds from our previous study, $3 \mathrm{~b}$, and $2 \mathrm{a}$, to further evaluate their cytotoxic activities against various molecular subtypes of human $\mathrm{BC}$ cell lines.

\section{Materials and Methods}

\section{Cell lines and cell culture}

Four breast cancer cell lines including MCF-7 (Michigan Cancer Foundation-7, ER+/PR+ HER2-, ATCC HTB 22), SKBR-3 (ER $-\mathrm{PR}^{-}$ER2+, ATCC HTB 30), MDA- MB-231 (ER ${ }^{-} / \mathrm{PR}^{-}$HER2 ${ }^{-}$, ATCC HTB 26), MDA-MB- 468 (ER ${ }^{-} / \mathrm{PR}^{-} \mathrm{HER} 2^{-}$, ATCC HTB 132) were obtained from cell bank of Pasteur Institute of Iran. All of these cells grow in monolayer and characterized by an epithelioid morphology. The cells were cultured in Roswell Park Memorial Institute (RPMI)-1640 medium (Biosera, France) supplemented with 100 unit $/ \mathrm{ml}$ penicillin, $100 \mu \mathrm{g} / \mathrm{ml}$ streptomycin as well as $10 \%$ fetal bovine serum (FBS) for MCF-7, MDA-MB-231 and MDA-MB-468 cell lines except for SKBR-3 which 20\% FBS was used (all from Biosera, France). The cells were then incubated at 37 in the $\mathrm{CO}_{2}$ incubator with a humidified atmosphere. Once the cells reached $80 \%$ confluency, they were treated by $0.25 \%$ trypsin-EDTA solution to be detached and counted.

\section{Cell counting}

To distinguish viable and dead cells, trypan blue dye exclusion staining was used. Trypan blue can incorporate into dead cells due to their damaged membrane and stain dead cells while the live cells remain unstained. To do this, after trypsinization, the cells were gently swirled to earn a homogeneous mixture. Then $10 \mu \mathrm{l}$ trypan blue solution were mixed with $10 \mu \mathrm{l}$ cell suspension and applied to a hemocytometer. The live unstained cells were counted and the number of viable cells per 1 milliliter was measured using the following formula:

Number of viable cells $=$ Counted unstained cells/\# of squares $\times 10000 \times 2$ (as dilution factor $) \times$ Total volume of cell suspension

\section{Formazan-based viable cell assay (MTT assay)}

The cytotoxic effect of each Ptx compounds was determined using a3-(4, 5-dimethylthiazol-2-yl)-2, 5-diphenyl-2H-tetrazolium bromide (MTT)

assay. In the first step, the optimal cell number was determined for the MTT assay.

\section{Determining optimal cell counts}

To determine the optimal cell count and incubation period for each cell line, adherent cells were released by trypsinization. Harvested cells were washed and a serial dilution of the cells $\left(1 \times 10^{6}\right.$ to $1 \times 10^{3}$ cells per $\left.\mathrm{ml}\right)$ was prepared in culture medium. $100 \mu 1$ of each dilution was then added into each well of a 96-well microplate in a sextuplicate manner. Three control-wells of medium alone were also included to provide the blanks. The cells were then incubated for 24 hours to recover under appropriate conditions. After cells reattached, the culture media was completely discarded and $100 \mu 1$ MTT reagent $(500 \mu \mathrm{g} / \mathrm{ml})$ was added to each well, including controls and blanks. The plate was returned to the $\mathrm{CO}_{2}$ incubator for 4 hours and periodically was checked under an inverted microscope for the appearance of visible formazan crystals. After complete removing the MTT solution, $150 \mu \mathrm{l}$ DMSO was added to all wells and the plate was ledft at room temperature in the dark for 1 hour. After dissolving all crystals, the plate cover was removed and the absorbance in each well including blanks was measured at $490 \mathrm{~nm}$ in a microplate ELISA reader. A plot of optical density (OD) versus cell concentration was obtained and the optimal number of cells for the assay was determined within the linear portion of the curve with an absorbance value between 0.75 and 1.25 . The optimal cell number was obtained $15 \times 10^{3}$ cells for all cell lines except for MDA-MB-468 which was 10 x $10^{3}$ cells.

\section{Cytotoxic effect of Ptx complexes}

After determining the optimal cell number, depending on the cell line, $10-15 \times 10^{3}$ cells were plated per well and incubated for 24 hours. The cells were then treated with different concentrations of each compound in a triplicate manner and incubated for more 24 hours. A $20 \mathrm{mM}$ stock solution of each Ptx complexes was prepared in dimethyl sulfoxide (DMSO) (Sigma-Aldrich, Germany) and diluted into the culture medium with a final concentration of 1 to $200 \mu \mathrm{m} / \mathrm{ml}$. Three cell-based wells treated with equivalent DMSO concentration were also used as the controls. Three wells with only culture medium were included as blanks. After 24 hours, the treatment media were completely discarded and $100 \mu \mathrm{l}$ of culture media containing $500 \mu \mathrm{g} / \mathrm{ml}$ MTT reagent was added to each well including controls and incubated for 4 hours until purple precipitates were visible. The MTT media were then discarded and $150 \mu \mathrm{DMSO}$ solution was added to each well and left at room temperature in the dark for 1 hour. Finally, the OD of each well was read at $492 \mathrm{~nm}$ using an ELISA plate reader.

\section{Data analysis and interpretation}

Each experiment was separately repeated at least three times. For each compound, the inhibitory effect was measured by using the following formula:

Inhibition $(\%)=100-(($ ODtest-ODblank $) /$ ODnegative $\times 100$ )

A curve of concentration versus inhibition was then generated using individual data points in GraghPad Prism ver. 6 (Inc., USA). The concentration which was required for $50 \%$ inhibition of the cell growth was reported as $\mathrm{IC}_{50}$ of each compound. The data expressed as mean $\pm \mathrm{SD}$, using Microsoft Excel 2010. GraphPad Prism 6 software (GraphPad Software, San Diego, CA, USA) was used for statistical analyses and drawing the graphs. $P$ values less than 0.05 were considered statistically significant. 
Table 1. In Vitro Cytotoxic Activity of Platinum (II) Complexes on Human Breast Cancer Cell Lines

\begin{tabular}{lcccc}
\hline Compound & \multicolumn{4}{c}{$\mathrm{IC}_{50} *(\mu \mathrm{M} \pm \mathrm{SD})$} \\
\hline & SKBR3 & MDA-MB-231 & MBA-MB-468 & MCF-7 \\
3b & $18 \pm 0.31$ & $7.92 \pm 0.24$ & $23.06 \pm 0.56$ & $7.1 \pm 0.12$ \\
2a & $49.21 \pm 1.21$ & $22.04 \pm 0.2$ & $44.71 \pm 0.41$ & $39.18 \pm 1.21$ \\
cis-platin & $221.30 \pm 5.80$ & $77.29 \pm 0.81$ & $105.9 \pm 4.10$ & $96.34 \pm 0.81$ \\
\hline
\end{tabular}

*The concentration required to produce $50 \%$ inhibition of cell growth compared to control experiments. The data are presented as mean $\pm \mathrm{SD}$.

\section{Results and discussion}

Previous studies revealed that platinum-based anti-cancer drugs are highly effective in the treatment of a wide range of human cancers including cervical, ovarian, neck, lung carcinomas as well as breast cancer [10]. Nevertheless, besides side effects, resistance to the common clinical drugs i.e. cis-platin and carboplatin [11], encourage researchers to develop new chemotherapeutic agents to be replaced with the old ones. In this regard, cyclometalated platinum (II) complexes are deliberated as promising anticancer agents [12]. In our previous study, we designed and synthesized new cycloplatinated complexes containing various phosphorus-based ligands [9]. The results of that study showed that these complexes had desirable biological activities against various cancer cell lines. In the present study, we selected two of the most effective compounds and extended the evaluation of their cytotoxic activities on other breast cancer cell lines with different clinical and molecular characteristics. Breast tumors are commonly classified into four molecular subtypes: basal-like (ER-/PR-/ HER2-, also known as Triple-Negative Breast Cancer: TNBC), luminal A(ER+/PR+/-/HER2-), luminal B(ER+, $\mathrm{PR}+/-, \mathrm{HER} 2+$ ), and HER2 enriched (ER-/PR-/HER2+) tumors. Prognosis, as well as response to therapies, are different for each subtype [13]. The patients with luminal

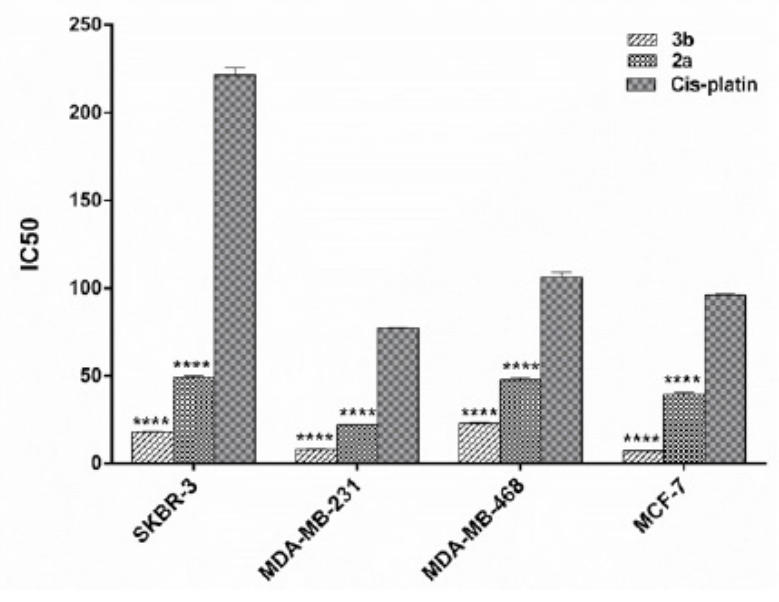

Figure 1. $\mathrm{IC}_{50}$ Diagrams of Platinum (II) Complexes on Human Breast Cancer Cell Lines Comparing Cis-platin; Human breast cancer cell lines (MCF-7, SKBR-3, MDA- MB-231, MDA-MB- 468) were treated with different concentration of platinum (II) complexes as well as cis-platin for 24 hours. Data are presented as mean \pm SD of inhibitory concentration $50\left(\mathrm{IC}_{50}\right)$ obtained from three separate tests. $* * * *$ Difference is significant at $<0.0001$ level (2-tailed).
A and luminal B tumors, due to the expression of ER and/PR, are responsive to hormone therapy. Similarly, the HER2 enriched tumors are potential candidates for treatment with anti-HER2 agents i.e. trasuszumab; whilst basal tumors are mostly characterized by poor prognosis and more aggressive phenotypes and their treatment are more difficult. Regarding BC cell-lines, MDA-MB-231 and MDA-MB-468 belong to a basal-like classification with ER-/PR-/HER2- phenotype; MCF-7 is a luminal classified cell line with $\mathrm{ER}+/ \mathrm{PR}+/ \mathrm{HER} 2-$ profile; and SKBR-3 belongs to Her2 enriched subtype (ER-/PR-ER2+) [14].

The in-vitro cytotoxic activity of the selected platinum (II) derivatives against four mentioned human BC cell lines were evaluated using colorimetric MTT cytotoxic assay. From the data obtained (Figure 1), it is clear that $3 \mathrm{~b}$ and $2 \mathrm{a}$, both, exhibited more promising anti-cancer activities against breast carcinoma cell lines comparing to cis-platin, as a standard drug which is commonly used in the clinic for treatment of patients with $\mathrm{BC}$ especially triple negative patients [15]. As could be observed in the Table 1, $3 \mathrm{~b}$ had the most cytotoxic effect on MCF-7 and MDA-MB-231 with $\mathrm{IC}_{50} \mathrm{~s}$ of $7.1 \pm 0.12$ and $7.92 \pm 0.24(\mu \mathrm{M} \pm \mathrm{SD})$, respectively. The best result for $2 \mathrm{a}$ was also obtained on MDA-MB-231, a representative of basal-like $\mathrm{BC}$, with the $\mathrm{IC}_{50}$ of $22.04 \pm 0.2$. As illustrated in Figure 1, statistical analysis also indicated that $3 \mathrm{~b}$ complex had significantly better activity on $\mathrm{BC}$ cell lines than cis-platin (4.5 to 13.5 times, $\mathrm{P}<0.0001$ ). Though these ratios are less in the case of $2 \mathrm{a}$, this compound also showed better activity than cis-platin ( 2.2 to 4.44 times, $\mathrm{P}<0.0001)$. The results collectively introduce these compounds as potentially valuable agents to be more evaluated in in-vitro and in-vivo studies as a promising anti-cancer agent in particular for triple negative breast cancers.

\section{Acknowledgments}

This study is a part of an MSc thesis written by Fatemeh Ebrahimi, which was financially supported by Bushehr University of Medical Sciences, Bushehr, Iran [Grant No. 124] and Shiraz University of Medical Sciences [Grant No. 95-01-16-12713].

\section{References}

1. Ahmad A. Breast cancer metastasis and drug resistance: Springer; 2013.

2. Benson JR, Jatoi I. The global breast cancer burden. Future oncology. 2012;8(6):697-702.

3. Jamieson ER, Lippard SJ. Structure, recognition, and 
processing of cisplatin- DNA adducts. Chemical reviews. 1999;99(9):2467-98.

4. Rosenberg B, Vancamp L, Krigas T. INHIBITION OF CELL DIVISION IN ESCHERICHIA COLI BY ELECTROLYSIS PRODUCTS FROM A PLATINUM ELECTRODE. Nature. 1965;205:698-9. Epub 1965/02/13.

5. Dasari S, Tchounwou PB. Cisplatin in cancer therapy: molecular mechanisms of action. European journal of pharmacology. 2014;0:364-78.

6. Zhang CX, Lippard SJ. New metal complexes as potential therapeutics. Current opinion in chemical biology. 2003;7(4):481-9. Epub 2003/08/28.

7. Wang D, Lippard SJ. Cellular processing of platinum anticancer drugs. Nature reviews Drug discovery. 2005;4(4):307-20. Epub 2005/03/25.

8. Fereidoonnezhad M, Niazi M, Ahmadipour Z, Mirzaee T, Faghih Z, Faghih Z, et al. Cyclometalated Platinum(II) Complexes Comprising 2-(Diphenylphosphino)pyridine and Various Thiolate Ligands: Synthesis, Spectroscopic Characterization, and Biological Activity. European Journal of Inorganic Chemistry. 2017;2017(15):2247-54.

9. Fereidoonnezhad M, Niazi M, Shahmohammadi Beni M, Mohammadi S, Faghih Z, Faghih Z, et al. Synthesis, Biological Evaluation, and Molecular Docking Studies on the DNA Binding Interactions of Platinum (II) Rollover Complexes Containing Phosphorus Donor Ligands. ChemMedChem. 2017;12(6):456-65.

10. Dasari S, Tchounwou PB. Cisplatin in cancer therapy: molecular mechanisms of action. European journal of pharmacology. 2014;740:364-78. Epub 2014/07/25.

11. Florea AM, Busselberg D. Cisplatin as an anti-tumor drug: cellular mechanisms of activity, drug resistance and induced side effects. Cancers (Basel). 2011;3(1):1351-71. Epub 2011/01/01

12. Johnstone TC, Suntharalingam K, Lippard SJ. The Next Generation of Platinum Drugs: Targeted Pt(II) Agents, Nanoparticle Delivery, and Pt(IV) Prodrugs. Chem Rev. 2016;116(5):3436-86. Epub 2016/02/13.

13. Holliday DL, Speirs V. Choosing the right cell line for breast cancer research. Breast cancer research : BCR. 2011;13(4):215. Epub 2011/09/03.

14. Shahriari S, Rezaeifard S, Moghimi HR, Khorramizadeh MR, Faghih Z. Cell membrane and intracellular expression of toll-like receptor 9 (TLR9) in colorectal cancer and breast cancer cell-lines. Cancer biomarkers : section A of Disease markers. 2017;18(4):375-80. Epub 2017/01/21.

15. Wahba HA, El-Hadaad HA. Current approaches in treatment of triple-negative breast cancer. Cancer biology \& medicine. 2015;12(2):106-16. Epub 2015/07/16.

\section{(ब) $\odot \odot$}

This work is licensed under a Creative Commons AttributionNon Commercial 4.0 International License. 